\title{
Stimulus dimensionality and discrimination learning in elementary schoolchildren*
}

\author{
C. F. ETAUGH and B. R. ANKNEY \\ Bradley University, Peoria, Ill. 61606
}

Ninety 6-, 8-, and 10-year-old children were presented with either two-dimensional or three-dimensional stimuli in a three-choice simultaneous size discrimination task. As predicted, two-dimensional and three-dimensional stimuli were discriminated equally well at all age levels. The results, in conjunction with previous findings that 3 to 5-year-olds discriminate three-dimensional stimuli more readily than two-dimensional ones, support Wohlwill's (1962) hypothesis that older children are less reliant on perceptual redundancy than are younger children.

Several investigators have shown that stimulus dimensionality exerts a strong influence on the discrimination learning of young children. Studies of children ranging from 3 to 5 years old almost always have found that three-dimensional stimuli are discriminated more easily than two-dimensional ones (Alberts \& Ehrenfreund, 1951; Dornbush \& Winnick, 1966; Etaugh \& Van Sickle, 1971; Falk, 1968; Kraynak \& Raskin, 1971; Kuenne, 1946; Stevenson \& Langford, 1957). The data for 6-year-olds, however, are less consistent. Some studies of this age group have reported faster discrimination of three-dimensional than of two-dimensional stimuli (Etaugh, 1970; Stevenson \& McBee, 1958), while others have failed to find dimensionality effects (Etaugh, Graffam, \& Turton, 1972; Falk, 1968). Dornbush \& Winnick (1966), using 7 -year-old Ss, also found no differences in the ease of discriminating two- and three-dimensional stimuli. One interpretation of these results is that the influence of stimulus dimensionality on discrimination learning diminishes with age. Such a trend, if substantiated, is consistent with Wohlwill's (1962) hypothesis that the developing child's increasing conceptual abilities decrease his reliance on redundant information such as that contained in three-dimensional stimuli.

Although the evidence cited previously hints at a decrease in the influence of dimensionality around 6 to 7 years of age, only Dornbush \& Winnick (1966) have used children as old as 7 years, and there appear to be no investigations of children older than 7 .

The purpose of the present experiment was to examine the effects of stimulus dimensionality on the size discrimination learning of children older than those

\footnotetext{
* The authors thank Larry D. Reid, who sponsors and takes full editorial responsibility for this paper, as well as the administration of the East Peoria public schools and the principal and teaching staff at Lincoln School for their cooperation in securing $\mathrm{Ss}$.
}

usually studied. Children of ages 6,8 , and 10 years were tested. It was predicted that no dimensionality effects would be found.

\section{METHOD \\ Subjects}

The Ss were 51 girls and 39 boys attending a middle-class public elementary school in East Peoria, Illinois. Girls slightly outnumbered boys in each of the grades tested. Thirty children each from kindergarten, second, and fourth grades-mean ages $5.8,7.6$, and 9.8 years, respectively-were assigned randomly to either the two-dimensional or the three-dimensional condition.

\section{Apparatus and Stimuli}

A modified Wisconsin General Test Apparatus was used (see Falk, 1968, for a detailed description). It consisted of a sliding stimulus tray containing three wells and a one-way vision screen behind which $\mathrm{E}$ arranged the stimuli.

The stimuli for the two-dimensional condition were three black paper squares, $2,2 \frac{1}{2}$, and 3 in. on a side, each pasted on $33 / 4$-in.-sq white cardboard, weighing $1 / 2 \mathrm{oz}$. The stimuli for the three-dimensional conditions consisted of three black wooden cubes, $2,2 \frac{1}{2}$, and 3 in. on a side, and weighing $1-7 / 8,4 \frac{1}{4}$, and $61 / 4 \mathrm{oz}$, respectively.

\section{Procedure}

The $\mathrm{S}$ was seated in front of the apparatus and was told he could learn to get marbles, which could be traded for a toy. The stimulus tray was brought forward, revealing the three stimuli appropriate to S's condition. The E lifted each stimulus in turn, indicating the well under each one, and told $S$, "Your job is to lift the block (picture) you think the marble is under."

A noncorrectional procedure was used. The criterion for learning was five consecutive correct responses, a commonly used criterion in three-choice discrimination tasks (e.g., Etaugh, Graffam, \& Turton, 1972; Etaugh \& Van Sickle, 1971; Falk, 1968; Stevenson \& McBee, 1958). Training was discontinued when $S$ reached criterion or at the end of 60 trials, whichever came first.

The position of the stimuli on the tray (left, middle, right) was determined by a prearranged random order, with the restriction that no stimulus appeared in the same position more than twice in a row. Each of the three stimuli was correct for one-third of the Ss in each condition. When the experiment was completed, the $\mathrm{S}$ was allowed to choose an inexpensive toy.

This procedure was used in a previous demonstration of the dimensionality effect in young children (Falk, 1968).

\section{RESULTS AND DISCUSSION}

Table 1 presents the means and standard deviations for errors to criterion for all groups. A 2 (dimensionality condition) by 3 (age) analysis of variance was performed on these scores. Neither the main effects nor the interaction between them was significant. At each age level, an unequal-N 2 (dimensionality condition) by 2 (sex) analysis of variance was run on the error scores, in order to test for possible sex differences. The results indicated that the performance of boys and girls did not 
Table 1

Means and Standard Deviations for Errors to Criterion

\begin{tabular}{lccc}
\hline & \multicolumn{3}{c}{ Age Group (Years) } \\
\cline { 2 - 4 } & 6 & 8 & 10 \\
\hline Two-Dimensional & & & \\
$\quad$ Mean & 27.27 & 26.07 & 32.13 \\
$\quad$ SD & 14.94 & 14.64 & 12.25 \\
Three-Dimensional & & & \\
$\quad$ Mean & 24.73 & 21.33 & 28.00 \\
SD & 16.06 & 16.08 & 14.71 \\
\hline
\end{tabular}

differ, and that there were no significant interactions between sex and dimensionality condition at any age level. Kraynak \& Raskin (1971), in their study of the dimensionality effect in preschool children, also reported no sex differences.

In summary, stimulus dimensionality had little affect on the size discrimination learning of 6- to 10-year-old children, as predicted. Although there was a slight tendency for three-dimensional stimuli to be discriminated more easily than their two-dimensional counterparts, this effect did not approach significance at any age level. These results, together with previously cited findings that dimensionality effects are strong for 3. to 5-year-olds but inconsistent for 6-year-olds, support Wohlwill's (1962) hypothesis that the increasing conceptual abilities of the older child decrease his dependence on the kind of redundant perceptual information contained in three-dimensional stimuli.

The fact that some investigators of 6-year-olds have found stimulus dimensionality effects while others have not suggests that this age is transitional with respect to the influence of dimensionality. These data are congruent with many other findings, summarized by White (1965), indicating that the character of children's learning changes between the ages of 5 and 7, becoming more symbolic, abstract, and "cognitive."

\section{REFERENCES}

Alberts, E., \& Ehrenfreund, D. Transposition in children as a function of age. Journal of Experimental Psychology, 1951, 41, 30-38.

Dornbush, R. L. \& Winnick, W. A. The relative effectiveness of stereometric and pattern stimuli in discrimination learning in children. Psychonomic Science, 1966, 5, 301-302.

Etaugh, C. F. Factors in learning stereometric discriminations in children. Perceptual \& Motor Skills, 1970, 30, 614.

Etaugh, C. F., Graffam, K. A., \& Turton, W. J. Effects of stimulus complexity and dimensionality on children's discrimination of forms. Perceptual \& Motor Skills, 1972, 36, 83-86.

83-86.
Etaugh, C. F., \& Van Sickle, D. J. Discrimination of three-dimensional objects and photographs of objects by children. Child Development, 1971, 42, 1680-1682.

Falk, C. T. Object and pattern discrimination learning by young children as a function of availability of cues. Child Development, 1968, 39, 923-931.

Kraynak, A. R., \& Raskin, L. M. The influence of age and stimulus dimensionality on form perception by preschool children. Developmental Psychology, 1971, 4, 389-393.

Kuenne, $M$. Experimental investigation of the relation of language to transposition behavior of young children. Journal of Experimental Psychology, 1946, 31, 257-271.

Stevenson, H. W., \& Langford, T. Time as a variable in transposition by children. Child Development, 1957, 28, 365-370.

Stevenson, H. W., \& McBee, G. The learning of object and pattern discriminations by children. Journal of Comparative \& Physiological Psychology, 1958, 51, 752-754.

White, S. H. Evidence for a hierarchical arrangement of learning processes. In L. P. Lipsitt and C. C. Spiker (Eds.), Advances in child development and behavior. Vol. 2. New York: Academic Press, 1965.

Wohlwill, J. F. From perception to inference: A dimension of cognitive development. In W. Kessen and C. Kuhlman (Eds.) Thought in the young child. Monographs of the Society for Research in Child Development, 1962, 27 (2, Serial No. 83) $73-93$.

(Received for publication October 24, 1972.) 